\title{
VOLUME DE PRISMAS E PIRÂMIDES: UMA ATIVIDADE NO ENSINO REMOTO
}

\author{
Elisângela Fouchy Schons ${ }^{1}$; Eleni Bisognin²
}

\section{RESUMO}

A atividade apresentada faz parte do segundo ciclo de aplicação do artefato pedagógico constituinte de uma tese de doutorado. Foi planejada, executada e avaliada junto a estagiários em seus estágios de regência em turmas de Ensino Médio. Teve por objetivo proporcionar aos estudantes do Ensino Médio a compreensão do cálculo de volume de prisma e pirâmide com o auxílio de materiais manipuláveis. Foi estruturada segundo as quatro fases propostas por Reeves (2000) para a Pesquisa Baseada em Design. Em função da pandemia da Covid-19 foi realizada de forma remota e o levantamento dos seus dados se deu através da gravação dos encontros de planejamento e aplicação e de anotações feitas pelo grupo de pesquisa e a apreciação dos mesmos pela Análise por Triangulação. Teve boa aceitação pelos alunos do Ensino Médio que participaram da sua aplicação. Para os estagiários o seu planejamento e realização foram um desafio, porque os fez buscar por alternativas, recursos e adaptações para o seu desenvolvimento de forma on-line, mas também contribuiu com a construção e o aperfeiçoamento de seus Conhecimentos Matemáticos para o Ensino.

Palavras-chave: Pesquisa Baseada em Design; Geometria; Pandemia; Formação de professores.

Eixo Temático: Educação, Cultura e Comunicação

\section{INTRODUÇÃO}

O professor, no processo de ensino e aprendizagem, se constitui como um elemento decisivo, pois é ele quem tem o papel de gerenciar, facilitar e interagir com os alunos a fim de obter resultados exitosos na busca pelo melhor aprendizado. Ele, também é o agente fundamental no desenvolvimento do seu conhecimento profissional e das suas práticas (FERREIRA, VALE e PIMENTEL, 2012). Por esse

\footnotetext{
${ }^{1}$ Professora de Matemática do Instituto Federal Farroupilha - campus JC e Doutoranda do curso de pós-graduação em ensino de Ciências e Matemática - UFN. elisangela.schons@iffarroupilha.edu.br

${ }^{2}$ Orientadora. Professora Doutora do Curso de Pós-graduação em ensino de Ciências e Matemática - UFN. eleni.bisognin@gmail.com
} 
motivo, a formação de professores é um tema que atrai a atenção de pesquisadores.

Em relação a formação dos professores de Matemática, Ball e seus colaboradores ao investigarem os saberes envolvidos na docência introduziram, inspirados no trabalho de Shulman, o conceito de "Conhecimento Matemático para o Ensino", o qual envolve todo "o conhecimento matemático necessário para realizar o trabalho de ensinar Matemática aos alunos" (BALL et al, 2008, p. 395). Segundo os autores, esse conhecimento está presente em todas as tarefas realizadas pelo professor e o seu desenvolvimento é um fator importante para melhorar a prática deste e, por conseguinte, a aprendizagem da Matemática por parte dos alunos.

A resolução CNE/CP nำ2/2019 ao definir as Diretrizes Curriculares Nacionais para a Formação Inicial em Nível Superior de Professores para a Educação Básica apresenta como um dos seus princípios norteadores o "reconhecimento de que a formação de professores exige um conjunto de conhecimentos, habilidades, valores e atitudes, que estão inerentemente alicerçados na prática" (BRASIL, 2019, p.4) e que essa prática deve estar presente desde o início do curso, mas com maior centralidade nos estágios com o propósito de efetivar o compromisso com metodologias inovadoras e com outras dinâmicas formativas que propiciem ao futuro professor aprendizagens significativas e contextualizadas.

Uma metodologia inovadora que apresenta "grande potencial gerador de estratégias de interação e colaboração na busca de soluções práticas para os problemas da educação, ao mesmo tempo que visa contribuir para o desenvolvimento de conhecimento teórico-metodológico" é a Pesquisa Baseada em Design. (REIS e AMIEL, 2019, p.299)

A Pesquisa Baseada em Design (PBD) é uma metodologia que busca, a partir de intervenções em sala de aula, desenvolver teorias, métodos, artefatos e práticas que colaborem com o processo de ensino e aprendizagem. Para Pessanha (2017) ela pode ser apresentada e estudada com professores em formação, porque através dela é possível executar um processo reflexivo centrado no planejamento didático, implementação prática e análise. Sendo assim, nesse artigo se apresentará uma atividade planejada, aplicada e avaliada junto a estagiários em seus estágios de regência em turmas de Ensino Médio. Ela faz parte do artefato pedagógico criado 
EDUCAÇÃO, SAÚDE

ETECNOLOGIA

26 A 28 DE OUTUBRO DE 2021

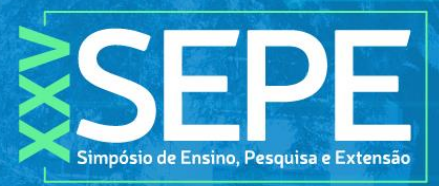

QUFN

pelo grupo de pesquisa do qual os estagiários participavam juntamente com a pesquisadora doutoranda, autora desse artigo, e teve por objetivo proporcionar aos estudantes do Ensino Médio a compreensão do cálculo de volume de prisma e pirâmide com o auxílio de materiais manipuláveis.

\section{METODOLOGIA}

A pesquisa de doutorado, da qual faz parte a atividade que é relatada, é de cunho qualitativo e tem por objetivo geral analisar as contribuições da metodologia de Pesquisa Baseada em Design na construção de conhecimentos para o ensino de Geometria Espacial por estagiários de um curso de Licenciatura em Matemática e está na fase de análise dos dados coletados. O levantamento desses dados se deu através da gravação dos encontros realizados, de entrevista e anotações feitas pelos participantes da pesquisa a fim de analisar os domínios do Conhecimento Matemático para o Ensino dos professores em formação, a partir da Análise por Triangulação.

Fez uso da Pesquisa Baseada em Design (PBD) por ela ser uma metodologia flexível e destinada a melhorar as práticas educacionais em contextos reais de aprendizagem com base na colaboração entre pesquisadores e profissionais (WANG e HANNAFIN, 2005). Essa colaboração aconteceu a partir da constituição de um grupo de pesquisa, o qual, segundo Gravemeijer e Coob (2013) pode ser composto por um ou mais pesquisadores e os professores das turmas, nesse caso, os estagiários de um curso de Licenciatura em Matemática de uma instituição de ensino da região central do Rio Grande do Sul, em seus estágios de regência em turmas do primeiro ano do curso Técnico em Agropecuária integrado ao Ensino Médio da mesma instituição.

$\mathrm{Na}$ PBD as intervenções acontecem em ciclos dos quais os resultados obtidos em um servem de base para reformulação dos outros. Por esse motivo a pesquisa foi planejada para ter duas aplicações, dois ciclos, em anos letivos diferentes, e seguindo as quatro fases propostas por Reeves (2000): análise do problema educativo, desenvolvimento do artefato pedagógico, intervenção em contextos reais de aprendizagem e análise retrospectiva para elaborar um redesign do artefato e/ou da aplicação. 
A atividade "Volume de prismas e pirâmides" foi uma das seis que integraram o artefato que faz parte da pesquisa de doutorado e foi construído pelo grupo de pesquisadores e estagiários. Foi aplicada nos dois ciclos da pesquisa.

A primeira aplicação aconteceu no ano letivo de 2019, de forma presencial, quando dois dos estagiários estavam realizando seus estágios. Na ocasião, o grupo de pesquisa, durante o planejamento da atividade, decidiu por realizá-la a partir de uma atividade investigativa na qual os alunos do Ensino Médio manusearam sólidos geométricos (prismas e pirâmides de mesma área da base e altura) para estudar o conteúdo de volume de prismas e pirâmides e a relação entre eles ${ }^{3}$.

A segunda aplicação foi realizada durante o ano letivo de 2020 por quatro estagiários divididos em duas duplas ${ }^{4}$ e de forma remota. A mudança no modelo de ensino e na organização dos estágios aconteceu em função da pandemia de Covid19. Como os encontros presenciais foram suspensos, todas as atividades letivas passaram a acontecer via videochamada, com cada um dos envolvidos em sua casa, inclusive os encontros do grupo de pesquisa passaram a ser a distância.

Em função destas mudanças a atividade precisou ser reformulada, pois como trabalhar com os sólidos geométricos e em grupo se os estudantes estavam cada um em sua casa. Essas mudanças foram conversadas pelo grupo e diferentes ideias foram discutidas, pois o interesse de todos era que a atividade permanecesse nos mesmos moldes da aplicada no ano anterior, visto que ela despertou o interesse dos estudantes do Ensino Médio e atingiu os objetivos propostos para ela.

Sendo assim, o grupo de pesquisa decidiu que para introduzir o conceito de volume e a relação das suas unidades de medida com as de capacidade, solicitaria aos estudantes que no dia da atividade tivessem em mãos uma embalagem de leite. Para estudar a relação entre os volumes do prisma e da pirâmide usariam de uma situação problema e por fim, com uso do GeoGebra iriam mostrar as relações apresentadas e estudadas anteriormente. Com a atividade planejada os estagiários

\footnotetext{
${ }^{3}$ O relato dessa atividade foi apresentado no SEPE de 2020, no trabalho "Volume de prismas e pirâmides: análise de uma atividade de ensino".

${ }^{4}$ Os estagiários serão designados por: Estagiário EO e estagiário PA, pertencentes a uma dupla, e Estagiário CS e estagiária TB a outra dupla.
} 
EDUCAÇÃO, SAÚDE

ETECNOLOGIA

26 A 28 DE OUTUBRO DE 2021

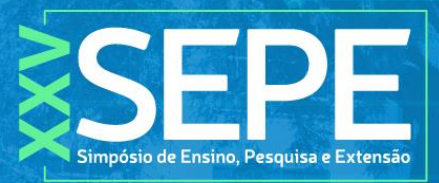

TRABALHO COMPIETO

passaram para a fase da aplicação, a qual foi gravada e acompanhada pela pesquisadora e a professora orientadora do estágio deles.

\section{RESULTADOS E DISCUSSÕES}

No dia da aplicação da atividade, em cada uma das turmas, tinham três alunos do Ensino Médio presentes, os que sempre compareciam nas aulas e, apesar de não abrirem suas câmeras, eram bastante participativos respondendo as perguntas feitas oralmente ou pelo chat de conversa. Conforme havia sido solicitado pelos professores estagiários, todos tinham suas caixas de leite a mão. A atividade iniciou com a exploração das caixas. Durante essa exploração os estagiários revisaram os conceitos já estudados por eles com os alunos, como as características, os elementos e o cálculo de área de um prisma. A partir dessa exploração chegaram ao cálculo de volume de um prisma e a relação entre as unidades de volume e capacidade.

Estagiário EO: Como podemos calcular o volume da caixa de leite?

Aluna AB: Pelo cálculo de volume, que é área da base vezes a altura.

Com base na resposta da aluna e a concordancia dos colegas, o professor estagiário e os alunos calcuram o volume de suas caixas de leite. Também conversaram sobre a unidade de medida utilizada para representar volume e a relação desta com a unidade de medida de capacidade.

Estagiário EO: Vocês perceberam que o volume representamos por $\mathrm{cm}^{3}$ e a quantidade de leite que tem na caixa é representado por Litro, como nós vamos fazer para transformar $\mathrm{cm}^{3}$ em litros? Qual a relação entre as unidades? Alguém tem uma sugestão?

Aluna AB: Professor, eu acho que um litro tem $1000 \mathrm{~cm}^{3}$ porque se 0 resultado do cálculo do volume da caixa deu $1008,2 \mathrm{~cm}^{3}$...

Estagiário EO: Muito bem!! Um litro tem $1000 \mathrm{~cm}^{3}$. Quantos $\mathrm{mL}$ tem esse litro? Dá pra criar uma relação entre os $\mathrm{cm}^{3}$ e os $\mathrm{mL}$ ?

Aluna EM: Um litro tem $1000 \mathrm{~mL}$...então $1 \mathrm{~mL}$ é igual a $1 \mathrm{~cm}^{3}$.

Estagiário EO: Isso mesmo. $1 \mathrm{~mL}$ equivale a $1 \mathrm{~cm}^{3}$. O volume da nossa caixa de leite é de $1008,2 \mathrm{~cm}^{3}$ e por isso é possível colocar 1 litro de leite dentro dela. 
Em ambas as turmas a introdução do assunto foi feita da mesma forma, diferenciando apenas os recursos utilizados, enquanto os estagiários EO e PA utilizaram da embalagem de leite e dos recursos tecnológicos, a dupla CS e TB utilizou da embalagem e da filmagem da realização dos cálculos. Na Figura 1, mostra-se os cálculos realizados pela dupla junto de seus alunos para encontrar o volume da caixa de leite e a unidade de medida de volume. Observa-se que o volume da caixa de leite, nesses cálculos, foi de $980 \mathrm{~cm}^{3}$. Isso aconteceu porque os professores estagiários e seus alunos optaram por não utilizar as medidas exatas e sim valores inteiros no cálculo do volume da embalagem e, por esse motivo, todos sabiam que o resultado final seria um valor aproximado do real. Essa escolha foi importante para que eles pudessem conversar com seus alunos que ao utilizar de valores aproximados o resultado final também será um valor aproximado e, que em algumas situações isso é possível, mas em outras faz-se necessário a utilização dos valores exatos.

Figura 1: Cálculo de volume realizado pelos estagiários e seus alunos e a relação entre as unidades de medidas

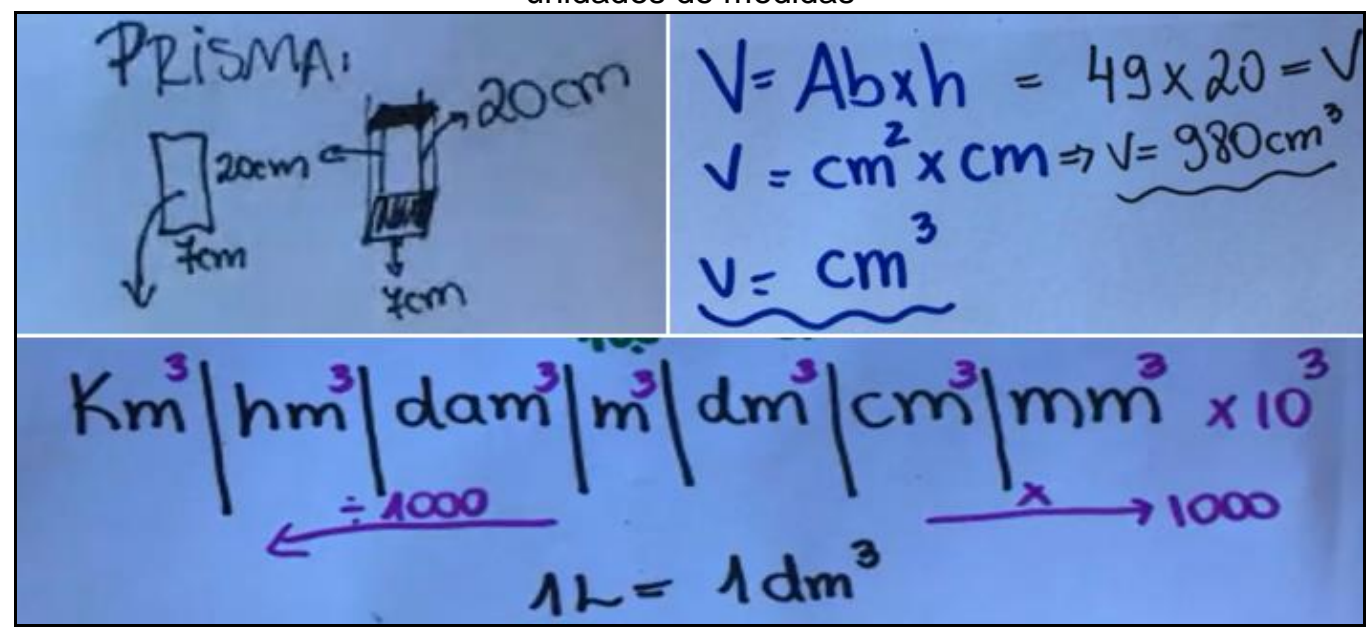

Fonte: autora

A seguir os estagiários apresentaram a situação problema para introduzir o cálculo de volume da pirâmide e a relação deste com o do prisma.

PA: Um dia dessa semana, eu e o professor EO acordamos inspirados e resolvemos fazer uma experiência, que é a seguinte: Como em casa tinha melancia para o café da manhã e nós estamos estudando os Poliedros com vocês, 
EDUCAÇÃO, SAÚDE

ETECNỎLGIA

26 A 28 DE OUTUBRO DE 2021

resolvemos construir um prisma e uma pirâmide, conforme a imagem mostrada (Figura 2). Pra ficar mais divertido, fizemos a pirâmide e o prisma com as mesmas medidas, ou seja, base quadrangular com arestas medindo $6 \mathrm{~cm}$ e a altura medindo $15 \mathrm{~cm}$.

Aluna AB: Essa altura é da pirâmide mesmo ou é a altura da face?

Estagiário EO: Essa pergunta que a $A B$ fez é bem importante porque uma coisa é a altura da pirâmide e outra é a altura da face. A altura da pirâmide reta é medida do vértice até o centro da sua base e a altura da face é medida do ponto médio da base do triângulo que constitui a face lateral até o seu vértice, é o apótema da pirâmide. Nesse caso a medida de $15 \mathrm{~cm}$ é a altura da pirâmide.

Figura 2: Prisma e pirâmides utilizados para ilustrar a situação problema

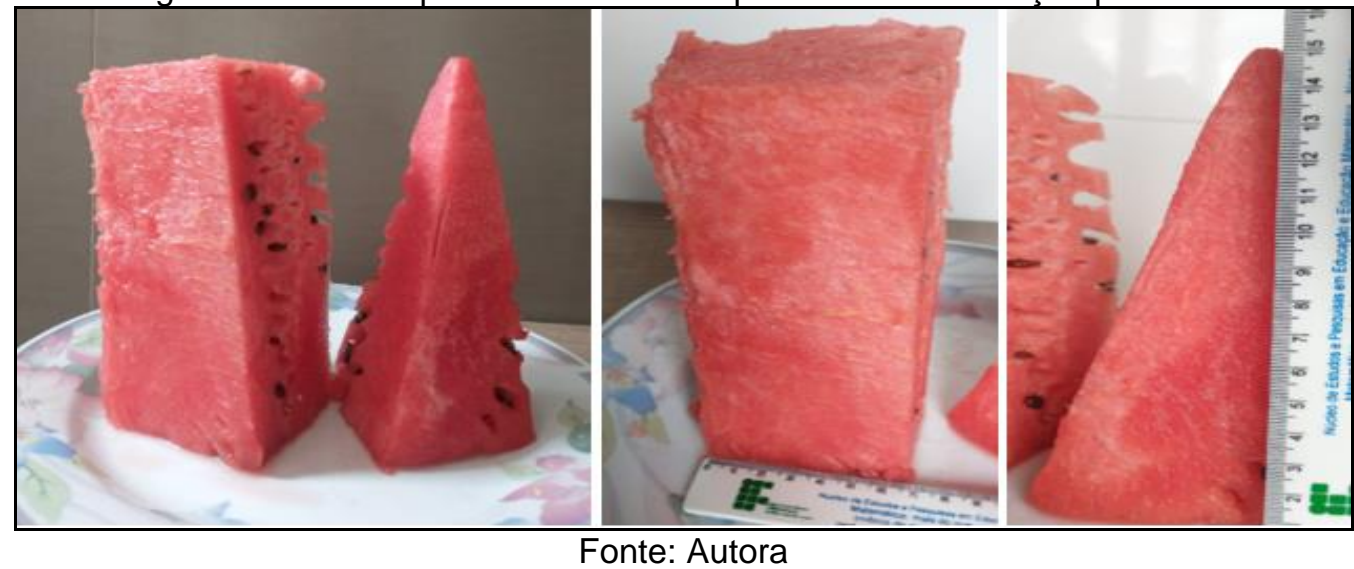

Estagiário PA: Agora queremos saber, se colocarmos cada um desses pedaços de melancia no liquificador e batermos para fazer suco, qual deles vai render mais suco? Ou vai render a mesma quantidade?

Aluna AB: Acho que a mesma quantidade.

Estagiário PA: Por quê?

Aluna AB: Porque eles têm as mesmas medidas.

Aluna EM: Acho que é o prisma, mas não tenho certeza...

Estagiário PA: Nós sabemos calcular o volume de um prisma, acabamos de ver com o professor EO, então como faremos para calcular o volume do prisma de melancia?

Aluna AB: Calcularemos a área da base e multiplicaremos pela altura. 
Estagiário PA: Ok, então o volume do prisma será $6 \mathrm{~cm} \times 6 \mathrm{~cm} \times 15 \mathrm{~cm}$ que é igual a $540 \mathrm{~cm}^{3}$. E da pirâmide, como faremos?

Aluna AB: Do mesmo jeito?

Estagiário PA: Pode ser...e quantidade de suco será a mesma então?

Aluna EM: Eu acho que não...

Estagiário PA: Pois bem, enquanto vocês vão pensando, eu vou mostrar que nós colocamos cada um dos pedaços de melancia no liquidificador, fizemos e suco e medimos a quantidade de suco gerada por cada um deles. $O$ resultado tá nas próximas imagens.

Na Figura 3 são mostradas as imagens que os estagiários apresentaram para os alunos. Na esquerda, a quantidade de suco que foi gerada a partir do prisma, um total de aproximadamente $470 \mathrm{~mL}$ e a direita, o suco da pirâmide, aproximadamente, $170 \mathrm{~mL}$.

Figura 3: Suco extraídos do prisma e da pirâmide de melancia

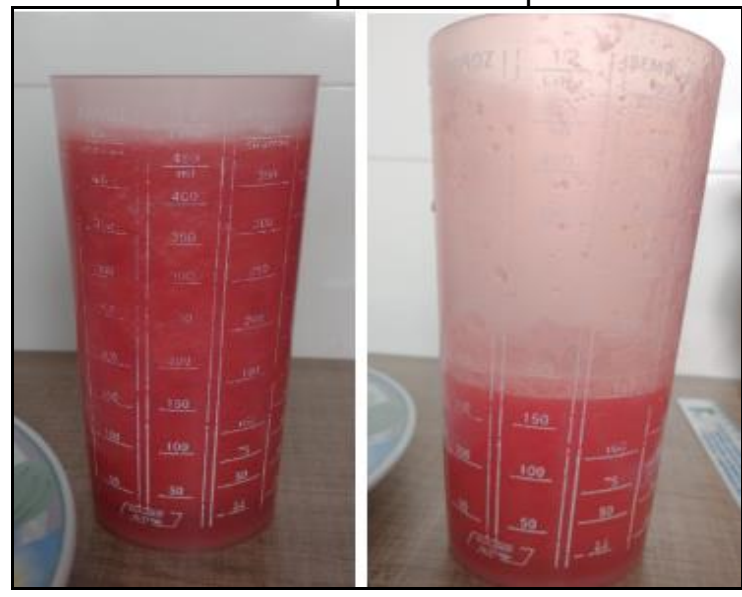

Fonte: Autora

A partir das imagens apresentadas os estagiários conversaram com os alunos. Primeiro sobre a quantidade de suco que foi extraído do prisma, que foi menor que o calculado por eles e o porquê de isso ter acontecido, como, o fato do pedaço de melancia não ser maciço, ter sementes que ocupam espaço e que na hora de fazer o suco esses não são contabilizados. Depois pediram para que estudantes procurassem encontrar uma relação entre as quantidades de suco produzidas com cada um dos pedaços de melancia e se seria possível determinar 
uma relação entre os volumes do prisma e da pirâmide, chegando na relação de que o volume da pirâmide é um terço do volume do prisma.

Os estagiários CS e TB também introduziram o assunto com a situação problema, apresentando as imagens do prisma e da pirâmide esculpidos na melancia e perguntando a seus alunos:

Estagiário CS: Vocês acham que o prisma e a pirâmide vão dar o mesmo volume de suco?

Alunos: Não. Acho que o prisma vai dar mais suco.

Estagiário CS: Por que vocês acham que o prisma vai dar mais?

Aluno MB: Porque ele tem mais área

Estagiário CS: Uma boa justificativa... porque nós podemos ver que enquanto o prisma mantém o mesmo formato da base até o topo, a pirâmide vai afinando, então vai perdendo área, massa e, consequentemente, vai perder volume também e o volume, como nós vimos, é um cálculo que depende de uma área então é por aí mesmo. Vamos para o suco...

Nesse momento os estagiários mostram a imagem apresentada na Figura 3.

Estagiária TB: Como vocês já haviam falado, a gente consegue perceber que o volume de suco do prisma é maior que o volume de suco da pirâmide. Como vocês podem ver, nós temos ali um valor aproximado de $470 \mathrm{~mL}$ de suco do prisma e $170 \mathrm{~mL}$ de suco da pirâmide. A gente acredita que tenha uma relação entre o volume do prisma e da pirâmide. Que relação a gente pode estabelecer entre eles?

Estagiário CS: Lembrem que esses valores não são precisos porque a melancia tem sementes, buraquinhos...essa quantidade de suco não vai ser o valor total do nosso volume, mas mesmo com essas quantidades a gente pode saber, mais ou menos, quantas vezes cabe o suco da pirâmide dentro do suco do prisma?

Aluna RC: Umas três vezes

Aluno MB: Quase três vezes

Estagiário CS: Mas como eu havia dito tem essa variação da semente e como o MB disse é quase três, mas numa relação mais precisa a relação entre o volume do prisma e da pirâmide é três. O volume da pirâmide é um terço do volume do 


\section{QUFN}

prisma. Nós trouxemos aqui uma demonstração no GeoGebra dessa relação e eu vou apresentá-la para vocês, para que vocês possam entender melhor.

Após as constatações feitas pelos estudantes e para ilustrar o que fora conversado, os estagiários, em ambas as turmas, apresentaram essa relação utilizando do GeoGebra. Na Figura 4 mostra-se imagens do material utilizado pelos estagiários.

Figura 4: Representação no GeoGebra da relação entre o volume da pirâmide com o volume do prisma

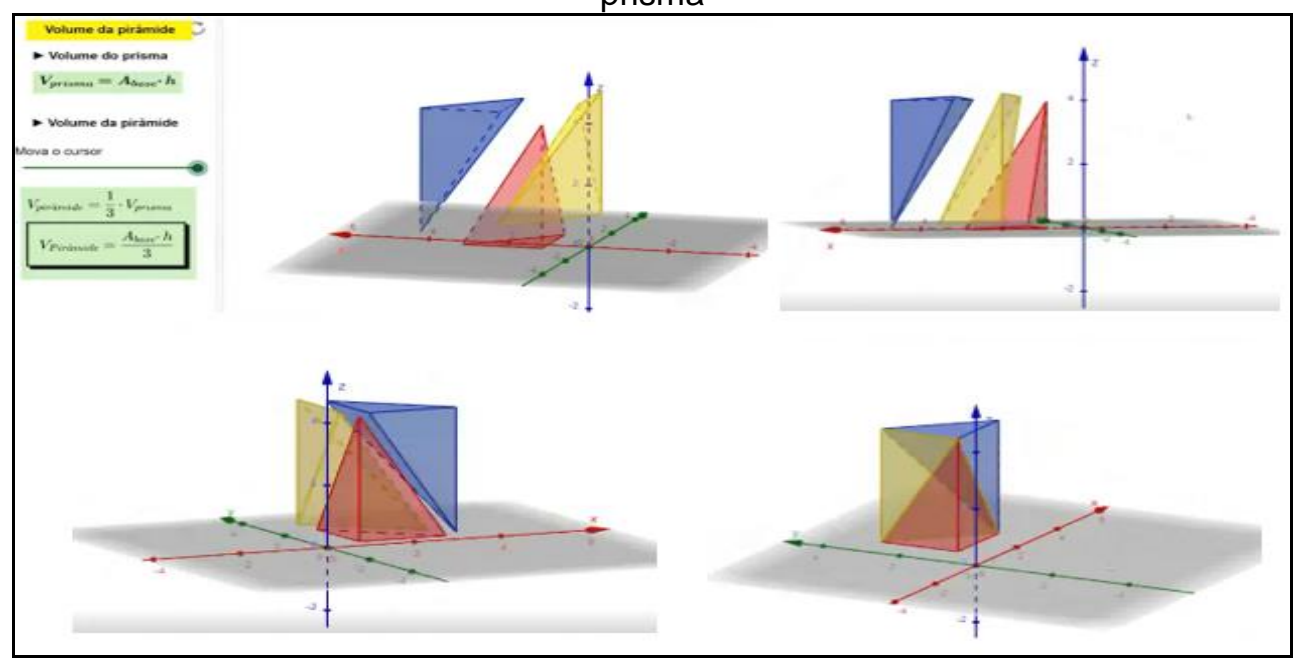

Fonte: Autora

Enquanto apresentavam no GeoGebra a constituição de um prisma triangular a partir de três pirâmides de base triangular, tendo todos a mesma área da base e a mesma altura, os estagiários aproveitaram para, novamente, explicar como calcular o volume do prisma e da pirâmide e a relação entre eles.

No encontro do grupo de pesquisa para avaliação da atividade, os estagiários colocaram que, em conversa com os alunos, esses disseram que gostaram da forma como a atividade foi proposta, principalmente da situação problema, que quando precisarem calcular o volume da pirâmide irão lembrar do que foi apresentado e que esse é um terço do volume do prisma. O grupo decidiu, também, que numa próxima realização da atividade, se tiver de ser de forma remota, ela pode seguir os moldes dessa aplicação. 


\section{CONCLUSÃO}

A atividade "Volume de prismas e pirâmides" teve boa aceitação pelos alunos do Ensino Médio que participaram da sua aplicação. Os estudantes participaram dela levando o material solicitado, fazendo cálculos, estimativas, respondendo às perguntas de seus professores e, principalmente, mostrando-se entusiasmados em averiguar através da experiência apresentada e do software GeoGebra como se efetiva o cálculo de volume dos prismas e pirâmides e a relação entre eles.

Para os estagiários o planejamento e a realização da atividade foram um desafio, pois ela teve sua elaboração e primeira aplicação no ensino presencial e para a segunda aplicação, em função das restrições colocadas pela pandemia do Coronavírus precisou ser reestruturada para o ensino remoto. Essa mudança fez com que o grupo de pesquisa repensasse o seu desenvolvimento e os recursos utilizados a fim de proporcionar aos estudantes do Ensino Médio a compreensão do cálculo de volume de prisma e pirâmide, buscando por situações e materiais que despertassem a curiosidade e $\mathrm{o}$ interesse dos estudantes pelo assunto.

Essas adaptações, ao ensino remoto e a busca por alternativas de ensino, foram importantes para o processo de formação destes professores porque os fez pensar em atividades que tem o aluno como um ser ativo, que constrói seu conhecimento e o professor como o agente que torna essa construção possível, e dessa forma eles também conseguiram desenvolver e aperfeiçoar os seus Conhecimentos Matemáticos para o Ensino.

A Pesquisa Baseada em Design no desenvolvimento dessa pesquisa tem se mostrado uma metodologia válida porque propõem o trabalho conjunto, nesse caso da pesquisadora com os estagiários, o que proporciona a troca de experiências, a colaboração mútua e a construção de conhecimentos matemáticos, assim como, a possibilidade de fazer o redesign da atividade aplicada em função do cenário da sua aplicação.

\section{REFERÊNCIAS}

BALL, D.; THAMES, M. H.; PHELPS, G. Content knowledge for teaching: What makes it special? Journal of Teacher Education, 59 (5), p. 389-407, 2008. 
BRASIL, Ministério da Educação. Conselho Nacional de Educação. Resolução CNE/CP 2, de 19 de fevereiro de 2002. Disponível em: $<$ http://portal.mec.gov.br/cne/arquivos/pdf/CP022002.pdf $>$. Acesso em: 15 de setembro de 2019.

FERREIRA, R. A. T.; VALE, I.; PIMENTEL, T. Conhecimento e práticas profissionais de professores de Matemática. In: ATAS DO XXIV SEMINÁRIO DE INVESTIGAÇÃO EM EDUCAÇÃO MATEMÁTICA. Braga: APM e CIEd da Universidade do Minho, 2013, p.335-344. Disponível em: [PDF] Conhecimento e práticas profissionais de professores de Matemática - Free Download PDF (silo.tips). Acesso em: 05 de setembro de 2021.

GRAVEMEIJER, K.; COBB, P. Design Research from the Learning Design Perspective. Educational Design Research. Part A: An Introduction, 2013, p.72113.

PESSANHA, M. A prática baseada em design: um modelo de ação reflexiva na formação de professores de ciências. In: XI ENCONTRO NACIONAL DE PESQUISA EM EDUCAÇÃO EM CIÊNCIAS - XI ENPEC. Santa Catarina: UFSC, 2017, pp. 1-13.

REEVES, T. C. Socially responsible educational technology research. Educational Technology, v. 40, n. 6, p. 19-28, nov./dez. 2000.

REIS, D.; AMIEL, T. Pesquisa baseada em design: um mapeamento sistemático da produção acadêmica em acesso aberto em língua portuguesa. In: SIMPÓSIO BRASILEIRO DE INFORMÁTICA NA EDUCAÇÃO, 30., 2019, Brasília. Anais [...]. Porto Alegre: SBC, 2019. Disponível em: https://brie.org/pub/index.php/sbie/article/view/8734/6295. Acesso em: 03 de junho de 2021.

WANG, F., \& HANNAFIN, M. J. Design-based research and technology-enhanced learning environments. Educational Technology Research and Development, 53(4), p. 5-23, 2005. 